\title{
Methotrexate Toxicity from Unintentional Dosing Errors: Calls to a Poison Center and Death Descriptions
}

\author{
John A. Thompson, MD, Jennifer S. Love, MD, and Robert G. Hendrickson, MD
}

Background: Methotrexate is a folate analog prescribed for varying disease with weekly administration as opposed to daily. Dosing errors can prove clinically significant and sometimes fatal.

Methods: We performed a retrospective poison center review of methotrexate calls between 2009 and 2019.

Results: Of 111 human-related poison center calls, most patients taking methotrexate were women ages 41 to 80 years old and were prescribed methotrexate for rheumatoid arthritis. Eighty-eight (79\%), and $41(36 \%)$ were admitted to the hospital. Thirty-one (75\%) of hospitalized patients received leukovorin treatment for their exposure. Two patients died from methotrexate dosing errors.

Discussion: Most methotrexate accidental ingestions reported to poison centers result from dose frequency errors. However, we note a higher incidence of unintentional therapeutic errors (79\% vs 13.7\%) than reported in the National Poison Data System in 2019. Patients are often hospitalized for lab monitoring, and many receive leucovorin.

Conclusions: Most methotrexate calls to our poison center resulted from taking the drug more often than prescribed. Efforts may focus on patient education, physician or pharmacist monitoring during initiation, improved dispensing devices, or weekly drug dispensing. ( $\mathrm{J}$ Am Board Fam Med 2021;34:1246-1248.)

Keywords: Drug-Related Side Effects and Adverse Reactions, Leucovorin, Medical Errors, Methotrexate, Poison Center, Retrospective Studies

\section{Introduction}

Methotrexate is a folate analog that inhibits RNA and DNA synthesis. It is prescribed for malignancies, organ transplantation, and autoimmune diseases-it is one of the recommended starting medications for rheumatoid arthritis by the American College of Rheumatology. ${ }^{1}$ While methotrexate may be initially prescribed by a subspecialist, comprehensive care

This article was externally peer reviewed.

Submitted 23 March 2021; revised 1 June 2021; accepted 4 June 2021.

From Oregon Poison Center, Portland, OR (JAT, JSL, RGH); Department of Emergency Medicine, Oregon Health \& Science University, Portland (JAT, JSL, RGH).

Funding: The authors received no funding for this research project.

Conflict of interest: The authors report no conflicts of interest.

Disclaimer: All authors listed on this manuscript have not published, posted, or submitted any papers from this same study.

Corresponding author: John A. Thompson, MD, 3181 SW Sam Jackson Park Rd., CSB-550, Portland, OR 97239 (Email: johnth@ohsu.edu). coordination through monitoring and prescription renewal may fall to the patient's family medicine physician. To avoid side effects and bypass saturable absorption, dosing is once weekly as opposed to daily, which can lead to fatal dosing errors. ${ }^{2}$ Side effects are numerous and range in severity from mild (e.g. stomatitis, nausea, vomiting, liver enzyme elevation) to severe (e.g. bone marrow suppression, hepatotoxicity, multiorgan toxicity resulting in death). ${ }^{3} \mathrm{We}$ describe methotrexate ingestions reported to the Oregon Poison Center from 2009 to 2019.

\section{Methods}

We performed a retrospective analysis of a regional poison center database that averaged 50,000 calls a year. The poison center database was queried for any ingestion from 2009 to 2019 that included "methotrexate" in the substances field. Cases were reviewed and categorized by multiple research staff. Case discrepancies were discussed until a consensus 
was reached. Descriptive statistics were used to analyze the data.

\section{Results}

We identified 146 cases, and 35 nonhuman ingestions were excluded (information only or pet exposure). Table 1 includes demographic information about 111 human-related ingestions. Seventy-nine (71\%) of patients were female, and most were older than age 40 years. Eighty-eight (79\%) were unintentional ingestions, and the most common were single additional dose errors. Two patients died $(2 \%)$ during this time period. One death was from an incorrectly written prescription by a physician resulting in a 6-fold dosing error. The second death was from a nurse-administered medication that was given as $15 \mathrm{mg}$ daily (instead of weekly as it was prescribed) for 6 days. Forty-one (36\%) patients were hospitalized after the ingestion, and 31 (75.6\%) of hospitalized patients received leucovorin treatment. The most common reason provided for taking an extra dose was the patient forgot it was taken earlier.

\section{Discussion}

Methotrexate ingestion in this study period (111 cases) is similar to previous poison center studies. $^{4,5}$ However, we note a higher incidence of unintentional therapeutic errors (79\% vs $13.7 \%$ ) than reported in the National Poison Data System (NPDS) for all ingestions in 2019. ${ }^{6}$ This discrepancy in incidence is likely multifactorial and may be accounted for by regional incidence of rheumatologic disease, differences in regional prescribing patterns, and variation in recognizing methotrexate toxicity during the study period.

Previous research focuses on acute methotrexate ingestions, and this study focuses on the unintentional ingestions. Unintentional ingestions diverged into 2 primary categories. The first, unintentional ingestions related to health care professional errors, resulted in the 2 deaths reported to our poison center. While rare, these deaths are important reminders to those administering methotrexate to use safety mechanisms to ensure proper dosing. The larger unintentional ingestion category, a single extra dose, still required hospitalization, treatment, and lab monitoring for some patients. Future research should
Table 1. Characteristics of Methotrexate Ingestions by Humans

\begin{tabular}{|c|c|c|}
\hline Characteristic & Number & $\%$ \\
\hline Total calls of ingestions & 111 & 100 \\
\hline \multicolumn{3}{|l|}{ Sex } \\
\hline Male & 32 & 29 \\
\hline Female & 79 & 71 \\
\hline \multicolumn{3}{|l|}{ Age (years) } \\
\hline 0 to 18 & 15 & 14 \\
\hline 19 to 40 & 15 & 14 \\
\hline 41 to 60 & 34 & 31 \\
\hline 61 to 80 & 36 & 32 \\
\hline 81 to 100 & 8 & 7 \\
\hline Not listed/unknown & 3 & 3 \\
\hline \multicolumn{3}{|l|}{ Ingestion type } \\
\hline Intentional & 23 & 21 \\
\hline Unintentional & 88 & 79 \\
\hline \multicolumn{3}{|l|}{ Unintentional subtype } \\
\hline Dose error & 13 & 15 \\
\hline One extra dose & 40 & 45 \\
\hline Multiple extra doses & 27 & 31 \\
\hline Pediatric exploratory & 8 & 9 \\
\hline Medication indication listed & 69 & 62 \\
\hline Rheumatoid arthritis & 38 & 55 \\
\hline Crohn's disease & 5 & 7 \\
\hline Psoriasis or psoriatic arthritis & 14 & 20 \\
\hline Other disease & 12 & 17 \\
\hline \multicolumn{3}{|l|}{ Treatment } \\
\hline Leucovorin treatment & 34 & \\
\hline Intentional ingestion & 12 & 35 \\
\hline Unintentional ingestion & 22 & 65 \\
\hline Sodium bicarbonate & 18 & \\
\hline Activated charcoal & 6 & \\
\hline Blood products & 4 & \\
\hline Steroids & 1 & \\
\hline Granulocyte stimulating factor & 2 & \\
\hline \multicolumn{3}{|l|}{ Course } \\
\hline Ingestions admitted to hospital & 41 & \\
\hline Intentional ingestion & 17 & 41 \\
\hline Unintentional—dose error & 2 & 5 \\
\hline Unintentional—one extra dose & 11 & 27 \\
\hline $\begin{array}{l}\text { Unintentional—multiple extra } \\
\text { doses }\end{array}$ & 8 & 20 \\
\hline $\begin{array}{l}\text { Unintentional—ediatric } \\
\text { exploratory }\end{array}$ & 3 & 7 \\
\hline $\begin{array}{l}\text { Admitted and leucovorin } \\
\text { treatment }\end{array}$ & 31 & 28 \\
\hline Intentional ingestion & 12 & 39 \\
\hline Unintentional ingestion & 19 & 61 \\
\hline Recorded signs of toxicity & 12 & 11 \\
\hline Death & 2 & 2 \\
\hline
\end{tabular}


examine interventions to minimize these accidental duplicate ingestions to aid in minimizing additional health care burdens to these patients.

Our results also highlight high rates of leucovorin use for treatment of hospitalized patients with methotrexate ingestion. Previous poison center studies noted leucovorin treatment rates of $14 \% .^{4}$ One potential reason for increased treatment rates may be increased awareness around leucovorin's lowcost, low-side-effect benefits, as well as difference in poison center recommendations by area. We strongly support leucovorin treatment for patients hospitalized for suspected methotrexate toxicity.

Fifteen (14\%) of methotrexate-related calls occurred in patients age 0 to 18 years old. Previous pediatric studies report low-dose ingestions, and most patients have good clinical outcomes. ${ }^{7}$ As new methotrexate formulations are developed, such as new "sweet-flavored" solutions, and dispensed in larger bottles, pediatric exposures with higher-dose ingestions may potentially increase. Poison centers should be prepared for triaging these exposures and referring them for medical evaluation.

This study has several limitations. Call records were incomplete, and low-risk calls often lacked follow-up information. In addition, patients with systemic infections or kidney injury may have been missed if the medication error was not disclosed or discovered.

\section{Conclusion}

Methotrexate's atypical dosing frequency can result in errors. Inappropriate methotrexate ingestions often result in hospitalizations and may require medical therapy and recurrent laboratory monitoring. Most methotrexate calls to our poison center resulted from taking the drug more often than prescribed. Regarding methotrexate prescribing and monitoring, an interdisciplinary effort may be an ideal approach. Efforts may focus on patient education, frequent physician or pharmacist monitoring in the medication initiation phase, improved devices for methotrexate dispensing (prescription bottle timer caps), or weekly drug dispensing.

To see this article online, please go to: http://jabfm.org/content/ 34/6/1246.full.

\section{References}

1. Singh JA, Furst DE, Bharat A, et al. 2012 update of the 2008 American College of Rheumatology recommendations for the use of disease-modifying antirheumatic drugs and biologic agents in the treatment of rheumatoid arthritis. Arthritis Care Res (Hoboken) 2012;64:625-39.

2. Radmanesh M, Rafiei B, Moosavi ZB, Sina N. Weekly vs. daily administration of oral methotrexate (MTX) for generalized plaque psoriasis: a randomized controlled clinical trial. Int J Dermatol 2011;50:1291-3.

3. Cumberland Pharmaceuticals Inc. Reditrex (methotrexate) [package insert]. U.S. Food and Drug Administration website. Available from: https:// www.accessdata.fda.gov/drugsatfda_docs/label/2019/ 210737s000lbl.pdf. Accessed May 11, 2021.

4. Bebarta VS, Hensley MD, Borys DJ. Acute methotrexate ingestions in adults: a report of serious clinical effects and treatments. J Toxicol 2014;2014: 214574.

5. Lovecchio F, Katz K, Watts D, Wood I. Four-year experience with methotrexate exposures. J Med Toxicol 2008;4:149-50.

6. Gummin DD, Mowry JB, Beuhler MC, et al. 2019 annual report of the American Association of Poison Control Centers' National Poison Data System (NPDS): 37th annual report. Clin Toxicol (Phila) 2020;58:1360-541.

7. Hays H, Beuhler MC, Spiller HA, et al. Evaluation of toxicity after acute accidental methotrexate ingestions in children under 6 years old: a 16-year multicenter review. Clin Toxicol (Phila) 2018;56:120-5. 